\title{
Effect of addition of Tunisian Zizyphus lotus L. Fruits on nutritional and sensory qualities of cookies
}

\author{
Youkabed Zarroug ${ }^{1 *}$, Jazia Sriti², Dorra Sfayhi ${ }^{3}$, Bechir Slimi ${ }^{3}$, Wafa Allouch ${ }^{\text {a }}$, Kamel Zayani ${ }^{4}$, \\ Khaoula Hammami ${ }^{2}$, Maryam Sowalhia ${ }^{1}$ and Mohamed Kharrat ${ }^{1}$
}

${ }^{1}$ Université de Carthage, Laboratoire des Grandes Cultures (LR16INRAT02), Institut National de Recherche Agronomique de Tunisie (INRAT), Ariana, Tunisie; ${ }^{2}$ Laboratoire des Substances Bioactives, Centre de Biotechnologie, Technopole BorjCedria, Hammam-Lif, Tunisie; ${ }^{3}$ Laboratoire des Nanomatériaux et Systèmes pour les Energies Renouvelables (LANSER), Centre de Recherches et des Technologies de l'Energie Technopole Borj Cedria, Hammam-Lif, Tunisie; ${ }^{4}$ Centre National des Recherches en Sciences des Matériaux (CNRSM), Technopôle de Borj-Cédria, Soliman, Tunisie

*Corresponding Author: Youkabed Zarroug, Université de Carthage, Laboratoire des Grandes Cultures (LR16INRAT02), Institut National de Recherche Agronomique de Tunisie (INRAT), Ariana, Tunisie. Email: zarrougyoukabed@yahoo.fr

Received: 26 June 2021; Accepted: 19 October 2021; Published: 7 December 2021

(c) 2021 Codon Publications

OPEN ACCESS (c)

PAPER

\begin{abstract}
Zizyphus lotus, which belongs to Rhamnaceae family, has been widely used to formulate many healthy food products. The aim of this work was to formulate new functional cookies enriched with different amounts of Zizyphus lotus powder (ZLP; 15\%, 30\%, 45\% and 100\%). The chemical properties of ZLP were also determined. The formulated cookies were evaluated for their physicochemical, textural and sensory characteristics. Results revealed that ZLP contained various bioactive components, fatty acids, and antioxidants. ZLP-added cookies demonstrated higher phytochemical and antioxidant activities than control cookies prepared without ZLP. The activity of ZLP cookies was enhanced with increase of ZLP level. Hardness and fracturability (brittleness) of cookies increased with increasing amount of ZLP. Results of Fourier-transform infrared spectroscopy and thermogravimetric analysis also revealed the presence of many bioactive compounds in formulated cookies. All cookie samples were generally accepted, but the panelists indicated a higher preference for cookies containing 15\% ZLP.
\end{abstract}

Keywords: antioxidants; cookies; phytochemical compounds; sensory characteristics; texture; Zizyphus lotus.

\section{Introduction}

Bakery products such as cookies are widely consumed around the world. This is mainly due to their higher energy, low cost, ready-to-eat nature, availability in different tastes and extended shelf life (Ajila et al., 2008). In addition, cookies may represent an excellent model product for enhancement of nutritional value and fortification. The main ingredients used for production of cookies are wheat flour, fat and sugar. To obtain homogeneous dough, water is also added. Nowadays, the enrichment of these cookies with vitamins, minerals, polyphenols and fibers is considered as a good alternative to produce high nutritional value foods to improve human health. To achieve this goal, many fruits and vegetable powders are used for the formulation of cookies such as papaya pulp flour, choke-berry extract, grape marc extract, sour cherry pomace extract and Japanese quince (Antoniewska et al., 2019; Molnar et al., 2015; Pasqualone et al., 2014; Šaponjac et al., 2016; Varastegani et al., 2015). In addition, many fruits being used are gaining attention because of attractive flavor as well as diverse antioxidant, anticarcinogenic and antimutagenic substances included in them (Antoniewska et al., 2019). Besides, the consumption of these products has health benefits against several chronic diseases, including cardiovascular disease and certain types of cancers (Ludwig et al., 2018). Genus Zizyphus belonging to Rhamnaceae family is widespread in tropical and subtropical regions: Asia, Africa, North America, South America, Oceania and Europe, with the center of diversity in Asia 
(Richardson et al., 2004). Besides, previous studies have described the secondary metabolites and pharmacology of genus Zizyphus. Traditionally, Zizyphus plant has been used in medicines to treat different diseases such as diarrhea, cholera, bronchitis, diabetes, hypertension, inflammation and intestinal spasms (El Maaiden, 2020; Le-Floc'h, 1983). In Tunisia, the commonly known species of Zizyphus shrub is Zizyphus lotus, which is named as 'Sedra', and its edible fruit is called 'Nbeg' (Mkadmini et al., 2015). Various studies have described the nutritional and beneficial effects of Zizyphus lotus fruits (Yamada et al., 1985). This small and round fruits are a rich source of sugar (Ghedira, 2013), minerals (calcium, magnesium, iron, sodium, potassium and phosphorus), carbohydrates, fatty acids and proteins (Abdeddaim et al., 2014). Authors have also highlighted the presence of large amounts of vitamins A, C and D (Chouaibi et al., 2011; Ghedira, 2013). Therefore, Owing to the presence of high healthy functional components, such as polyphenols, fibers, bioactive compounds, including micronutrients and phytochemicals (Da Silva et al., 2007), Zizyphus lotus fruits are widely consumed in many countries and used to formulate many food products such as pastes, purees, syrups and confections. Moreover, Zizyphus fruits are usually used as food additive in many bakery products to improve their technological quality and nutritional value. In this context, the aim of the present work was to characterize Zizyphus lotus fruit powder and to evaluate its effect on physicochemical properties and sensory evaluation of cookies.

\section{Materials and methods}

\section{Preparation of Zizyphus lotus powder}

Zizyphus lotus fruits were collected in July 2020 from Goubollat region of Beja in the northwest of Tunisia. The edible part of the fruits were manually isolated from seeds, sun-dried for $120 \mathrm{~h}$, and milled. The obtained samples were then sieved through a $75-\mu \mathrm{m}$ sieve to get fine powder of Zizyphus lotus fruits (ZLP) and finally stored in plastic containers at $4^{\circ} \mathrm{C}$ until further use.

\section{Chemical composition}

Moisture, protein, fat and ash contents of ZLP and cookie samples were determined according to the method described by Association of Official Analytical Chemists (AOAC, 2005). Total carbohydrate content was calculated by difference (100 - sum of protein, fat, ash and moisture). The results were expressed as g per $100 \mathrm{~g}$ of dry weight. Energy was calculated as follows:

\footnotetext{
Energy $(\mathrm{kcal} / 100 \mathrm{~g})=4 \times($ g protein + g carbohydrate $)+$ $9 \times(\mathrm{g}$ fat $)$.
}

The water activity (Aw) was determined using Aqua Lab (Meter, AquaLab Series 3TE, USA) at $25^{\circ} \mathrm{C}$. Each assay was carried out in triplicate.

\section{Techno-functional properties of ZLP}

Water absorption capacity (WAC) was determined according to the method described by Anderson et al. (1970). In a pre-weighed centrifuge tube, 1-g sample was mixed with $10-\mathrm{mL}$ distilled water. The tube was stirred for $2 \mathrm{~min}$ and then centrifuged at 3,000 rpm for $15 \mathrm{~min}$. The supernatant was decanted into a tared evaporating dish for determining its solid content and the sediment was weighed. The WAC was calculated as weight of sediment (g) per weight of sample (g) on a dry basis. Oil absorption capacity $(\mathrm{OAC})$ was determined according to the method described by Kaur and Singh. (2005). An amount of $0.5 \mathrm{~g}$ of sample was mixed with $6 \mathrm{~mL}$ of corn oil in preweighted centrifuge tubes, stirred for $1 \mathrm{~min}$, left for 30 $\mathrm{min}$ and centrifuged at 3,000 $\mathrm{g}$ for $25 \mathrm{~min}$. The separated oil volume was recorded and the tubes were inverted for 25 min to drain out the oil prior to reweighting. The OAC was expressed as gram of oil bound per gram of sample on a dry basis. Swelling index (SI) was determined by the procedure described by Rosell et al. (2009). An amount of $1 \mathrm{~g}$ of sample was transferred into a graduated cylinder, it was gently leveled and the volume was noted. Then $10 \mathrm{~mL}$ of distilled water was added to the sample; the cylinder was swirled and left to stand for $60 \mathrm{~min}$ while the swelling (change in volume) was recorded every $15 \mathrm{~min}$. The swelling index of samples was determined as a multiple of original volume.

\section{Fatty acid extraction and analysis}

Zizyphus lotus powder (20 g) was extracted in a Soxhlet apparatus with $250 \mathrm{~mL}$ of ether of petroleum at $40^{\circ} \mathrm{C}$. Between each step, the extract was filtered with a Whatman filter paper $\left(\mathrm{N}^{\circ} 4\right)$, concentrated under rotary vacuum evaporator (Rotovapor-El, Labortechnik AG, Büchi, Switzerland) at $40 \mathrm{C}$ and conserved at $4^{\circ} \mathrm{C}$ for analysis

Fatty acid composition of ZLP lipid fraction was determined as fatty acid methyl esters using gas chromatography (Agilent 19091S-433) equipped with a flame ionization detector and a polar phenylmethyl-siloxane capillary column $(60 \mathrm{~m} \times 25 \mathrm{~mm} \times 0.25 \mu \mathrm{m}$ film thickness) as described by Zarroug et al. (2015).

\section{Formulation of cookies enriched with ZLP}

Cookies were formulated according to the method described of Tyagi et al. (2020) with minor modification. 
The ingredients used for preparing cookies are as follows: wheat flour, ZLP, 25-g powdered sugar, 26-g margarine, $0.6-\mathrm{g}$ baking powder, $12-\mathrm{mL}$ water, $0.7-\mathrm{g}$ salt and 18-g whole eggs. Control cookie (CC) samples were prepared with wheat flour $(100 \%)$ and other ingredients whereas the enriched cookie samples were formulated using combinations of wheat flour and ZLP. The ZLP was incorporated into cookies at the following five levels: 0\% (CC), 15\% (C15), 30\% (C30), 45\% (C45) and $100 \%(\mathrm{C} 100)$ by replacing the equivalent amount of wheat flour from the formulation. For preparation of cookies, the process consisted of mixing wheat flour (or ZLP), margarine and sugar using a mixer (Kenwood, Poland) for $7 \mathrm{~min}$. Then whole eggs and required amount of water were added to this mixture with the rest of ingredients to obtain homogeneous dough. Prepared dough was rolled out to 2-mm thick circular shapes and biscuit dough was cut with a circular cutter to obtain pieces of 5-cm diameter. Finally, cookies were baked in oven (Convection, Type De Dietrich) at $175^{\circ} \mathrm{C}$ for $15 \mathrm{~min}$. The baked cookies were cooled for $30 \mathrm{~min}$ at ambient temperature and stored in air-tight bags for further analysis.

\section{Physical, color and textural analysis of cookies}

Physical parameters, including weight (g), thickness (T), diameter (D) and spread ratio $(\mathrm{D} / \mathrm{T})$ were determined for cookie samples according to the procedure described by Hussai et al. (2006). Color measurement of the surface of the studied cookie samples was determined by a Chromameter (Konika Minolta, Sensing INC, Japan) using the hunter $\mathrm{L}^{\circ}, \mathrm{a}^{\prime \prime}$ and $\mathrm{b}^{\prime \prime}$. The $\mathrm{L}^{\prime \prime}$ values measure black (0) to white (100), a" values measure redness $(+100)$ and greenness $(-100)$, and $b^{\circ}$ values measure yellowness $(+100)$ and blueness $(-100)$. The hardness of formulated baked cookies was studied by three-point bending tests at room temperature. A texture analyzer TAXT2i (Perten, TVT 6700, UK) was used with 1,000-N load cell and a sharp blade cutting probe (HDP/BSK blade set with knife). The distance between support bars was $4 \mathrm{~cm}$ and the probe travelling speed was set at $1 \mathrm{~mm} / \mathrm{s}$. Texture analysis were carried out in triplicate for each cookie formulation.

\section{Thermogravimetric analysis (TGA)}

Thermogravimetric analysis of cookie samples was carried out in TGA-4000 Perkin Elmer (CURIE GRANT) and analyzed by the Pyris Manager software. The analysis was carried out by standard protocol. Weight loss (weight\%) was observed with respect to temperature, and graphs were obtained for each sample with the Pyris software.

\section{Fourier-transform infrared spectroscopy (FTIR)}

Functional groups present in cookie samples were characterized by the Perkin Elmer FTIR instrument equipped with the software Perkin Elmer Spectrum Version 10.4.3. The samples were grinded with potassium bromide pellets and measured at a wavelength range of 400-4,000 $\mathrm{cm}^{\bigotimes 1}$.

\section{Scanning Electron Microscopy (SEM)}

Microstructure of baked cookies was evaluated using SEM (JEOL/JSM-5400) as described by Adebiyi et al. (2016). Cookies were milled, sieved and then observed using two magnification levels of $\times 400$ and $\times 1,500$.

\section{Phytochemical Analysis and Antioxidant Activities of ZLP and Formulated Cookies}

\section{Extract preparation}

Zizyphus lotus powder was extracted by maceration using the following solvents: acetone (60\%), ethanol $(60 \%)$, methanol $(60 \%)$ and water. This extraction was done according to the method described by Mau et al. (2001). Triplicate samples of $2.5 \mathrm{~g}$ of dry matter were extracted by mixing with $25 \mathrm{~mL}$ of solvent. The mixture was stirred for $30 \mathrm{~min}$ and kept in darkness for $24 \mathrm{~h}$ at $4^{\circ} \mathrm{C}$. Finally, this mixture was filtered with a Whatman filter paper $\left(\mathrm{N}^{\circ} 4\right)$ and concentrated under rotary vacuum evaporator at $40^{\circ} \mathrm{C}$. The dry residues were stored at $4{ }^{\circ} \mathrm{C}$ for further analysis. Each extraction was done in triplicate. For cookie samples, extracts were prepared using the method described by Blanco Canalis et al. (2020). Cookies were milled and defatted in $30-\mathrm{mL}$ hexane at $70^{\circ} \mathrm{C}$ for $20 \mathrm{~min}$. Cookie sample, $100 \mathrm{mg}$, was extracted with $1 \mathrm{~mL}$ of acetone:water $(70: 30 \mathrm{v} / \mathrm{v})$ mixture, and agitation in vortex was applied for $5 \mathrm{~min}$ at room temperature. Then the extracts were centrifuged for $10 \mathrm{~min}$ at $800 \times \mathrm{g}$ and supernatants were collected. The supernatants were filtered and stored for further analysis.

\section{Determination of total polyphenols (TPC), total flavonoids (TFC) and condensed tannins content (CTC)}

Content of TPC was determined using the FolinCiocalteu spectrophotometric method (UV-VIS) as described by Dewanto et al. (2002). TPC was expressed as milligram of gallic acid equivalent per gram of dry matter (mg EAG/g DW) through the calibration curve with gallic acid. For determining TFC, $250 \mu \mathrm{L}$ of methanolic extract was combined with $75-\mu \mathrm{L} \mathrm{NaNO}_{2}$ (5\%) (Dewanto et al., 2002). TFC levels were expressed in 
milligram of quercetin equivalent per gram of dry matter (mg EC/g DW). The protocol followed in the extraction of CTC was that recommended by Sun et al. (1998). CTC was expressed in milligram of catechin equivalent per gram of extract (mg CE/g DW).

\section{Antiradical activity}

Methanol extract, $1,000 \mu \mathrm{L}$, was added to $500 \mu \mathrm{L}$ of 2,2-diphenyl-1-picrylhydrazyl (DPPH, $0.2 \mathrm{mM}$; Hatano et al., 1988). After vigorous stirring, the mixture was kept at room temperature for $30 \mathrm{~min}$ in the dark and the absorbance was measured at $517 \mathrm{~nm}$. The antiradical activity was calculated as percentage of inhibition (PI) of DPPH using the following formula:

$$
\text { Percentage of inhibition }(\mathrm{PI})=\frac{\mathrm{Do}_{\text {control }}-\mathrm{Do}_{\text {extract }}}{\mathrm{Do} \mathrm{o}_{\text {control }}}
$$

where $\mathrm{DO}_{\text {control }}$ is the absorbance of control at $30 \mathrm{~min}$ and $\mathrm{DO}_{\text {extract }}$ is the absorbance of extract. The antiradical activity was finally expressed as $\mathrm{IC}_{50}\left(\mu \mathrm{g} \mathrm{mL}^{-1}\right)$. A lower $\mathrm{IC}_{50}$ value corresponds to a higher antioxidant activity of the extracted sample (Patro et al., 2005). All samples were analyzed in three replications.

\section{Reducing power}

This method consists of mixing $1,000 \mu \mathrm{L}$ of fraction at different concentrations with $1,250 \mu \mathrm{L}$ of phosphate buffer $(0.2 \mathrm{~mol} / \mathrm{L}, \mathrm{pH} 6.6)$ and $1,250 \mu \mathrm{L}$ of $\mathrm{K}_{3} \mathrm{Fe}(\mathrm{CN})_{6}(1 \%)$ (Ferreira et al., 2007). The solution was then kept in water bath for $20 \mathrm{~min}$ at $50^{\circ} \mathrm{C}$. To stop reaction, $1,250 \mu \mathrm{L}$ of trichloroacetic acid (TCA) (10\%) was added to the solution followed by centrifugation at $650 \mathrm{~g}$ for $10 \mathrm{~min}$ at $25^{\circ} \mathrm{C}$. Finally, at the intake of $1,250 \mu \mathrm{L}$ of supernatant, 1,250 $\mu \mathrm{L}$ of $\mathrm{H}_{2} \mathrm{O}$ and $250 \mu \mathrm{L}$ of $\mathrm{FeCl}_{3}(0.1 \%)$ were added to the solution and the absorbance was measured at $700 \mathrm{~nm}$.

\section{Sensory analysis of cookies}

Sensory analysis of cookies was conducted by 15 semitrained panelists (research students and laboratory staff) from the Field Crops Laboratory, INRAT, Tunisia. They were asked to evaluate cookie samples for flavor, color, texture, after taste and overall acceptability. After cooling, the cookies were coded and served to panelists in plastic containers with mineral water to cleanse the palate between each tasted sample. The scores were based on the following criteria: 9 = liked extremely; 8 = liked very much; 7 = liked moderately; $6=$ liked slightly; $5=$ neither liked nor disliked; 4 = disliked slightly; 3 = disliked moderately; 2 = disliked very much; 1 = disliked extremely. Average of the scores was calculated and rounded off to the nearest whole number. Sensory analysis of cookie samples was carried out in triplicate for each sample.

\section{Statistical analysis}

Each analytical determination was performed at least in triplicate. Values of different parameters were expressed as mean \pm standard deviation $(\bar{X} \pm S D)$. Statistical analyses were performed with the STATISTICA software. The Duncan's test was used to evaluate the significance of differences between mean values at $p<0.05$.

\section{Results and Discussion}

\section{ZLP characterization}

\section{Chemical composition and techno-functional properties of ZLP}

Results of chemical composition and techno-functional properties of ZLP are presented in Table 1.

The ZLP had a moisture content of 9.55\%, which was lower than those reported for ZL fruits from Algeria (Saadoudi et al., 2017), but was within the recommended moisture contents $(<14 \%)$ for safe storage, minimal microbial growth and chemical deterioration, leading to longer shelf life. Protein, fat and ash contents of ZLP were $2.64 \%, 5.37 \%$ and $3.01 \%$, respectively. Fat and ash contents in Tunisian ZLP were higher than those found by Choi et al. (2016) for Korean jujubes. However, the protein content in ZLP was higher than those found by Ghalem et al. (2014) (2.10\%) and Saadoudi et al. (2017) (1.43\%) in Zizyphus lotus from Algeria. The carbohydrates content in Tunisian ZLP, about 79.43\%, was lower than those found by Li et al. (2007) in five Chinese Zizyphus lotus cultivars (ranged from $80.86 \%$ to $85.63 \%$ ). The observed difference in chemical composition of ZLP depended on the location and the used species. In comparison to other fruit powders, the protein and ash contents in ZLP were lower than those found in the Tinospora cordifolia stem powder (proteins: $5.21 \%$ and ash: $6.26 \%$ ) by Tyagi et al. (2020).

Referring to the techno-functional properties of ZLP, the values of WAC, SI and OAC in ZLP were about 2.81 $\mathrm{g} / \mathrm{g}, 5.5 \mathrm{mg} / \mathrm{g}$ and $2.96 \mathrm{~g} / \mathrm{g}$, respectively. The obtained WAC (about $1.32 \mathrm{~g} / \mathrm{g}$ ) and OAC (about $1.20 \mathrm{~g} / \mathrm{g}$ ) values were higher than those detected in pearl millet flour (Adebiyi et al., 2016). The WAC of ZLP was lower than those found in some cereals, such as in rice bran (around $5.21 \mathrm{~g} / \mathrm{g}$ ) (Sangnark and Noomhorm, 2004) and fruit coproducts such as passion fruit $(13.5 \mathrm{~g} / \mathrm{g})$ and pineapple 
Table 1. Chemical composition and techno-functional properties of ZLP.

\begin{tabular}{lc} 
Parameters & ZLP \\
\hline Moisture (\%) & $9.55 \pm 0.07$ \\
Fat (\%) & $5.37 \pm 0.42$ \\
Protein (\%) & $2.64 \pm 0.07$ \\
Ash (\%) & $3.01 \pm 0.02$ \\
Carbohydrates (\%) & $79.43 \pm 1.6$ \\
Energy (kcal/100 g) & $388.65 \pm 2.92$ \\
SI (mg/g) & $5.5 \pm 0.02$ \\
WAC (g/g) & $2.81 \pm 0.07$ \\
OAC (g/g) & $2.96 \pm 0.22$ \\
Fatty acids (\% total fatty acid) & \\
$\quad$ Palmitic acid (C16:0) & $13.12 \pm 0.41$ \\
Stearic acid (C18:0) & $4.72 \pm 0.22$ \\
Arachidic acid (C20:0) & $1.00 \pm 0.01$ \\
$\quad$ Behenic acid (C22:0) & $0.92 \pm 0.06$ \\
Tetracosanoic acid (C24:0) & $0.60 \pm 0.02$ \\
Oleic acid (C18:1) & $55.73 \pm 0.85$ \\
10-Octadecenoic acid methyl ester (C19:1) & $0.96 \pm 0.05$ \\
Gadoleic acid (C20:1) & $2.64 \pm 0.01$ \\
Linoleic acid (C18:2) & $20.31 \pm 0.24$ \\
$\sum$ Saturated fatty acids (\%) & 20.36 \\
$\sum$ Monousaturated fatty acids (\%) & 59.33 \\
\& Polyunsaturated fatty acids (\%) & 20.31 \\
Ratio: Unsaturated:saturated fatty acids & 3.91 \\
\hline & \\
\hline
\end{tabular}

Values are expressed as mean \pm SD of three determinations. SI: swelling index; WAC: water absorption capacity; OAC: oil absorption capacity.

(14.6 g/g) (Martínez et al., 2012). As noted, the hydration properties of ZLP were related to the chemical structure of polysaccharides, proteins and the fruit source. However, OAC is the capability of vegetable apolar chain protein to physically bind lipids by capillary attraction. This interaction is essential in food applications, because oil is known as retainer of flavor and enhances mouthfeel of food-formulated products. In addition, a better SI improved functionality of flour, which would ultimately yield a good product (Adebiyi et al., 2016).

\section{Composition of fatty acids}

In ZLP, saturated fatty acids represented $20.36 \%$ of total fatty acids, while monounsaturated fatty acids accounted for $79.64 \%$. Nine fatty acids were identified, where oleic acid was the major one accounting for $55.73 \%$, followed by linoleic acid with $20.31 \%$ of total fatty acids (Table 1 ). Since ZL oil was rich in both oleic and linoleic acids, it might be considered healthier for human consumption. It has long been recognized that plant oils containing relatively low concentrations of omega- 6 and higher levels of monounsaturated fatty acids (mainly oleic acid) may contribute to the lower rate of coronary heart disease (CHD) and a nutritional perspective (Ryan et al., 2007). Other representative fatty acids were palmitic $(13.12 \%)$, stearic (4.72\%) and gadoleic (2.64\%) acids. In addition, arachidic, behenic, tetracosanoic and 10-octadecenoic acid methyl ester acids were minor fatty acids with contents varying from $0.60 \%$ to $1 \%$. These results are similar to those reported by Chouaibi et al. (2011) for ZL seed oil.

\section{Phytochemical composition and antioxidant activities of ZLP}

Total polyphenols, TFC and CTC of different extracts are summarized in Figure 1. The highest contents of TPC, TFC and CTC were obtained in the acetone (60\%) extract with values of $3.12 \mathrm{mg} \mathrm{GAE} / \mathrm{g}$ DW, $0.49 \mathrm{mg} \mathrm{CE} / \mathrm{g} \mathrm{DW}$ and $1.09 \mathrm{mg}$ CE/g DW, respectively. The lowest contents were recorded in the methanol fraction. According to Wojdyło et al. (2016), ZL fruit is considered as a rich source of bioactive components, including polyphenols, triterpenic acids, polysaccharides, nucleosides and nucleobases. In general, phenolic compounds in ZL fruit contribute to the antioxidant potential of its powder extracts. Authors have reported correlation between phenolic compounds and antioxidant activity (Elfalleh et al., 2011). Antioxidant activity of different extracts of ZLP was examined by its radical scavenging activity using the stable radical DPPH and by reducing powers (Table 2). Methanol (60\%) and acetone $(60 \%)$ fractions exhibited the uppermost antiradical capacities with $\mathrm{IC}_{50}$ reaching $70 \mu \mathrm{g} / \mathrm{mL}$ and $75 \mu \mathrm{g} / \mathrm{mL}$, respectively. The obtained results are lower than those found in Moroccan ZL $\left(\mathrm{IC}_{50}=477.6 \mu \mathrm{g} / \mathrm{mL}\right)$ using methanol solvent (70\%) (Bakhtaoui et al., 2014). Previous study conducted on ZL fruit from another region of Tunisia revealed $\mathrm{IC}_{50}=289 \mu \mathrm{g} / \mathrm{mL}$ (Mkadmini et al., 2015) and $310 \mu \mathrm{g} / \mathrm{mL}$ (Ghazghazi et al., 2014). The Zizyphus mauritiana fruits from Nigeria exhibited $\mathrm{IC}_{50}$ $=338.45 \mu \mathrm{g} / \mathrm{mL}$ (Okala et al., 2014), which was higher than the value obtained in the present study. The consequences of solvent on the antioxidant ability were also analyzed by determining reducing powers (Figure 1 ). The highest antioxidant potential was observed in acetone fractions $(330 \mu \mathrm{g} / \mathrm{mL})$. The obtained result was similar to that found in southern Tunisian ZL fruits $(289 \mu \mathrm{g} /$ $\mathrm{mL}$ ) (Mkadmini et al., 2015). The observed variability of phytochemical contents and antioxidant activities of Zizyphus genus could be explained by various factors, such as the geographical provenance, grown conditions, types of species and the nature of solvent used for extraction (Ksouri et al., 2008).

\section{Cookies characterization}

\section{Nutritional composition of formulated cookies}

Nutritional composition of enriched cookies with ZLP is presented in Table 2. Results established that the addition 

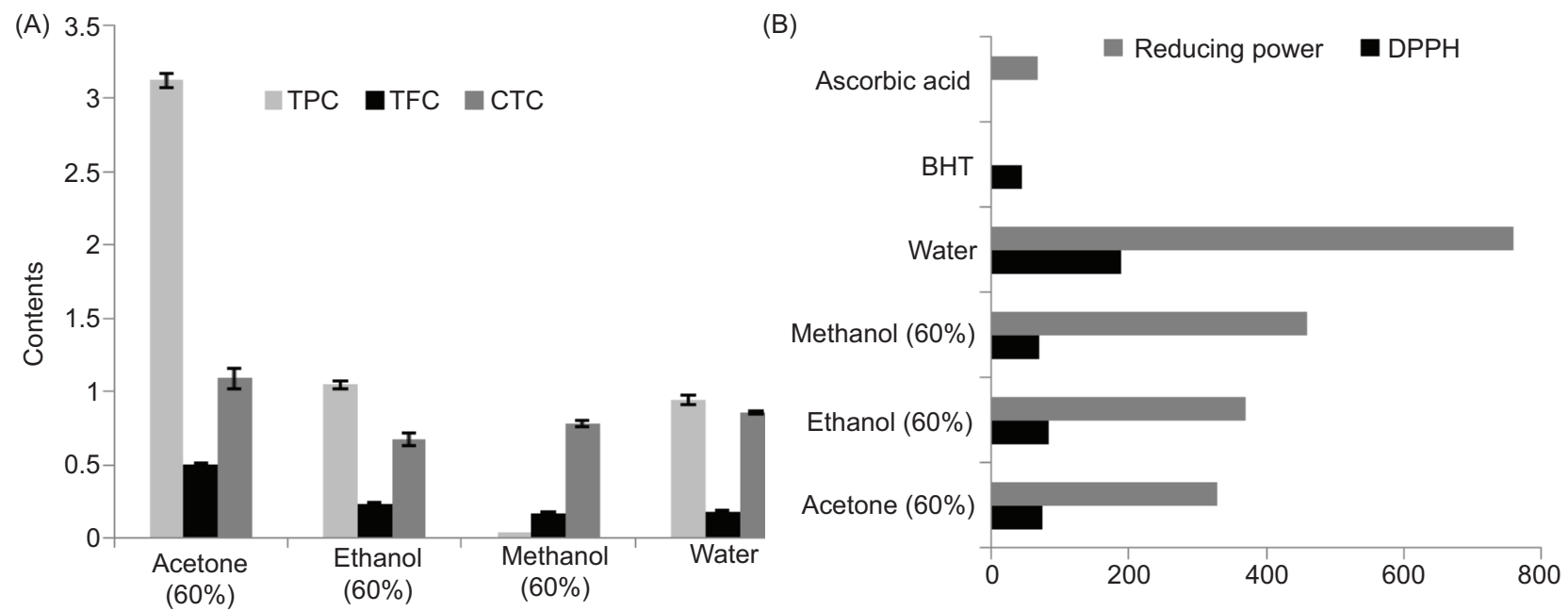

Figure 1. (A) TPC, TFC and CTC of different solvent extracts, and (B) antioxidant activities of ZLP. TPC: total polyphenols content (mg GAE/g MS); TFC: total flavonoids content (mg CE/g MS); CTC: condensed tannins content (mg CE/g MS); DPPH $\left(\mathrm{IC}_{50}, \mu \mathrm{g} / \mathrm{mL}\right)$; reducing power $\left(\mathrm{EC}_{50}, \mu \mathrm{g} / \mathrm{mL}\right)$; GAE: gallic acid equivalents; CE: catechin equivalents.

Table 2. Nutritional analysis of formulated cookies.

\begin{tabular}{lccccccc} 
Cookies & $\begin{array}{c}\text { Moisture } \\
(\%)\end{array}$ & $\begin{array}{c}\text { Fat } \\
(\%)\end{array}$ & $\begin{array}{c}\text { Protein } \\
(\%)\end{array}$ & $\begin{array}{c}\text { Ash } \\
(\%)\end{array}$ & $\begin{array}{c}\text { Carbohydrates } \\
(\mathrm{CHO} \%)\end{array}$ & $\begin{array}{c}\text { Water activity } \\
(\mathrm{Aw})\end{array}$ & $\begin{array}{c}\text { Energy } \\
(\mathrm{kcal} / 100 \mathrm{~g})\end{array}$ \\
\hline CC & $5.14 \pm 1.20^{\mathrm{e}}$ & $17.10 \pm 0.01^{\mathrm{a}}$ & $7.10 \pm 0.03^{\mathrm{e}}$ & $0.84 \pm 0.02^{\mathrm{a}}$ & $69.82 \pm 1.22^{\mathrm{a}}$ & $0.50 \pm 0.01$ & $461.58 \pm 4.57^{\mathrm{a}}$ \\
C15 & $6.55 \pm 0.3^{\mathrm{d}}$ & $18.90 \pm 0.01^{\mathrm{b}}$ & $6.60 \pm 0.02^{\mathrm{d}}$ & $0.92 \pm 0.03^{\mathrm{b}}$ & $67.03 \pm 0.34^{\mathrm{b}}$ & $0.53 \pm 0.02$ & $464.62 \pm 2.13^{\mathrm{a}}$ \\
C30 & $7.29 \pm 0.37^{\mathrm{c}}$ & $19.50 \pm 0.02^{\mathrm{c}}$ & $6.35 \pm 0.02^{\mathrm{c}}$ & $1.10 \pm 0.03^{\mathrm{c}}$ & $65.76 \pm 0.41^{\mathrm{c}}$ & $0.55 \pm 0.13$ & $463.94 \pm 1.33^{\mathrm{a}}$ \\
C45 & $7.62 \pm 2.48^{\mathrm{b}}$ & $19.70 \pm 0.01^{\mathrm{d}}$ & $6.06 \pm 0.02^{\mathrm{b}}$ & $1.03 \pm 0.01^{\mathrm{d}}$ & $65.59 \pm 2.48^{\mathrm{c}}$ & $0.57 \pm 0.01$ & $463.90 \pm 9.29^{\mathrm{a}}$ \\
C100 & $7.64 \pm 0.53^{\mathrm{a}}$ & $19.90 \pm 0.05^{\mathrm{e}}$ & $4.94 \pm 0.01^{\mathrm{a}}$ & $1.50 \pm 0.01^{\mathrm{e}}$ & $66.02 \pm 0.51^{\mathrm{d}}$ & $0.59 \pm 0.01$ & $462.94 \pm 1.21^{\mathrm{a}}$ \\
\hline
\end{tabular}

Mean values with different superscript alphabets in the same column differ significantly. CC: control cookies; C15, C30, C45, C100 are cookie samples containing wheat flour:ZLP in the ratio of $85: 15,70: 30,55: 45$ and $0: 100$, respectively.

of ZLP significantly increased $(p<0.05)$ the moisture, ash, fat and carbohydrates contents in cookies when compared to control cookies whereas protein values were decreased significantly.

In all formulated cookies, carbohydrates were the major component, followed by fat, protein, water and ash. Results demonstrated statistically significant differences $(p<0.05)$ between formulated cookies, especially for moisture, fat, protein and ash contents. Only for carbohydrates content, a nonsignificant difference was observed. Similar results revealed increase in ash and moisture contents in cookies enriched with spinach (5-15\%) (Galla et al., 2017) and Tinospora cordifolia stem (2-12\%) powders (Tyagi et al., 2020). In the same context, Bhat et al. (2020) reported consistent results in cookies containing tomato powder and crude lycopene. The energy values of enriched cookies ranged from $461.58 \mathrm{kcal}$ in CC sample to $464.62 \mathrm{kcal}$ in $\mathrm{C} 15$ sample. These results were in consistency with previous studies carried by Kaur et al. (2017) and Saadoudi et al. (2017) on cookies enriched with ZLP from Algeria and raw flaxseed flour. About water activity, similar to that observed for moisture content, addition of ZLP in cookies provoked a significant increase in this parameter. The highest water activity value was observed in C100 sample (0.59), but it was still below than that allowed for growth of microorganisms (Aw > 0.6) (Chieh, 2006). These findings were higher than those reported by Milićević et al. (2020), who revealed water activity values ranging from 0.297 to 0.411 in cookies prepared with wheat bran gels.

\section{Physical, textural and color characteristics of formulated cookies}

According to Pareyt and Delcour (2008), quality of good cookies is related to large piece diameter, tender but snapping final product, and uniform surface-cracking pattern. The physical, textural and color characteristics of formulated cookies are depicted in Table 3. The weight of cookies enriched with ZLP varied from $12.5 \mathrm{~g}$ in C15 sample to $13.27 \mathrm{~g}$ in C100 sample. After addition of ZLP, the weight of cookies increased significantly $(p<0.05)$ in 


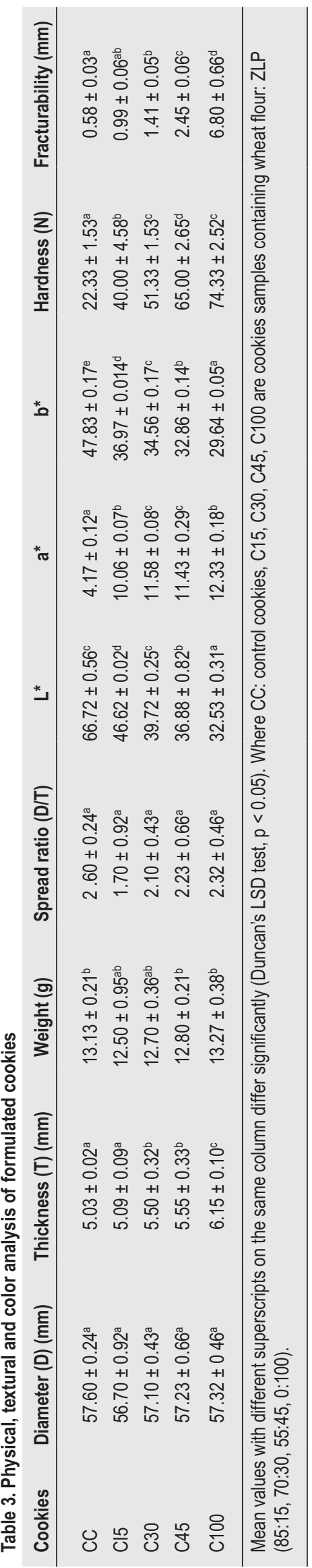

comparison to CC sample. This increase in the weight of cookies was related to the presence of dietary fibers in ZLP, which enables to bind with water molecules and prevents loss of moisture during baking process. These results are in the trend of those observed by Saadoudi et al. (2017) on biscuits made with Algerian ZLP. In all formulated cookies, the diameter ranged from $56.70 \mathrm{~mm}$ to $57.60 \mathrm{~mm}$. Maximum diameter was observed in CC sample, while minimum was in $\mathrm{C} 15$ cookie sample. These variations could be due to the dilution of gluten present in wheat flour. Results also demonstrated increase in the thickness of cookies from $5.03 \mathrm{~mm}$ (CC sample) to $6.15 \mathrm{~mm}$ (C100 sample). The obtained results of cookies enriched with ZLP are in accordance with the studies reported by Kaur et al. (2017) and Saadoudi et al. (2017) on some fortified cookies. A decrease in the spread ratio of cookies was observed with the inclusion of ZLP; this reduction could be due to the water absorption capacity of fibers present in ZLP. Similar results were obtained by Das Chagas et al. (2020), Ismail et al. (2014) and Toledo et al. (2017) when evaluating the effect of addition of by-products of pomegranate peels, pineapple, apple, melon, and camu-camu in cookies.

In order to evaluate the acceptability of prepared cookies by consumers, it is very important to determine their color parameters. The photographic images (Figure 2) of formulated cookies revealed that ZLP was the main ingredient that developed dark color, and C100 sample was the much darker cookies, looking like biscuits made with chocolate. The statistical analysis revealed a significant difference $(p<0.05)$ between all cookie samples regarding $L^{\prime \prime}$ and $b^{*}$ values. In addition, as observed in Table 4, $C C$ sample had the highest $L^{\prime \prime}$ and $b^{*}$ values as compared to the cookies enriched with ZLP. Moreover, addition of

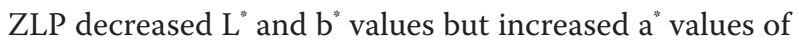
formulated cookies. These effects could be explained by the dark color of cookies because of added ZLP, which is related to its richness in natural pigments such as polyphenols (Ajila et al., 2008; Takeungwongtrakul and Benjakul. 2017). According to Masmoudi et al. (2021), the dark color of cookies could be also due to the more pronounced Maillard and caramelization reactions during the baking process, when wheat flour was substituted by ZLP containing higher content of sugar. These findings are in agreement with those of biscuits supplemented with Doum dietary fiber (Aboshora et al., 2019) and bamboo shoot powder (Ajila et al., 2008).

Regarding texture analysis, results revealed that the hardness and fracturability (brittleness) of cookies were increased significantly $(p<0.05)$ with the addition of ZLP. In all formulated cookies, C100 sample had the highest hardness and fracturability values $(74.33 \mathrm{~N}$ and $6.8 \mathrm{~mm}$ ) compared to CC sample (22.33 N and $0.58 \mathrm{~mm})$. Similar results were also observed in previous findings in 


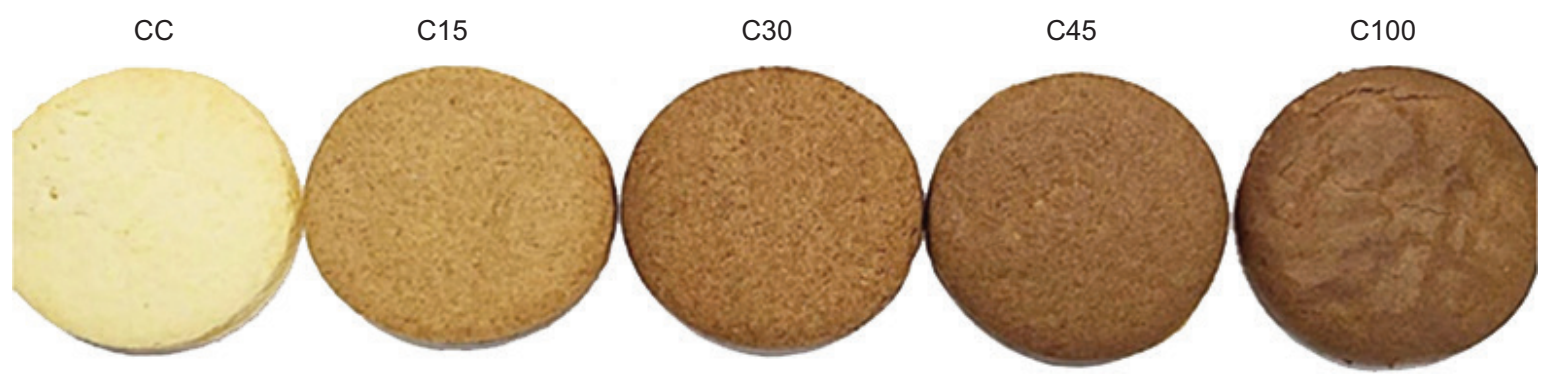

Figure 2. Photographic images of cookie samples. CC: control cookies, C15, C30, C45, C100 are cookie samples containing wheat flour:ZLP in the ratio of $85: 15,70: 30,55: 45$ and $0: 100$, respectively.

which cookies were enriched with bamboo shoot, spinach, Tinospora cordifolia stem and tomato powder (Ajila et al., 2008; Bhat et al., 2020; Galla et al., 2017; Tyagi et al., 2020). This increase in texture parameters are explained by the presence of ZLP, with high content of polysaccharides, which may lead to the dilution of gluten and extensive gluten structure. In addition, substituting ZLP for wheat flour in cookies formulation decreased its gluten content responsible for the viscoelastic character of dough. Das Chagas et al. (2020) affirmed in their study on cookies enriched with camu-camu coproduct powder that reduction of glutenin and gliadin proteins could have a remarkable effect on the formation of viscoelastic dough, which may possibly lead to increased hardness.

\section{TPC, TFC and CTC of cookies}

Table 4 reveals the TPC, TFC and CTC values of defatted methanolic extract of formulated cookie samples. Results revealed that the addition of ZLP increased significantly $(p<0.05)$ TPC, TFC and CTC in enriched cookie samples when compared to CC sample, and this increase was effectively due to the high content of phenolic compounds such as protocatechuic acid, gallic acid, chlorogenic acid, caffeic acid and ascorbic acid present in ZLP (Koley et al., 2016). In all formulated cookies, C100 sample contained the highest contents of TPC $(0.11 \mathrm{mg}$ GAE/g), TFC (0.05 mg QE/g) and CTC (1.07 mg QE/g). Our results were generally in agreement with the findings of other studies regarding the substitution of wheat flour in cookies by some fruit and vegetable powders such as apple, pineapple and melon coproducts (Toledo et al., 2017), watermelon rind powder (Naknaen et al., 2016) and camu-camu coproduct (Das Chagas et al., 2020).

\section{Antioxidant potential of cookies}

Table 4 indicates that the addition of ZLP in cookies significantly $(p<0.05)$ increased the free radical scavenging activity and reducing power as compared to $\mathrm{CC}$ sample. This implies that the addition of higher level of ZLP improved the antioxidant activity of cookie products. In all formulated cookies, the highest free radical scavenging activity and reducing power were observed in C100 sample. This observation was in accordance with previous studies carried out with incorporation of

Table 4. Phytochemical analysis and antioxidant activities of formulated cookies.

\begin{tabular}{|c|c|c|c|c|c|}
\hline \multirow[t]{2}{*}{ Cookies } & \multicolumn{3}{|c|}{ Phytochemical parameters } & \multicolumn{2}{|c|}{ Antioxidant activities } \\
\hline & $\mathrm{TPC}^{\mathrm{a}}$ & $\mathrm{TFC}^{\mathrm{b}}$ & CTC $^{b}$ & $\mathrm{DPPH}^{\mathrm{c}}$ & Reducing power ${ }^{d}$ \\
\hline CC & $<0.01$ & $0.01 \pm 0.01^{\mathrm{a}}$ & $0.57 \pm 0.14^{\mathrm{e}}$ & $454 \pm 0.54^{e}$ & $950 \pm 3.42^{\mathrm{e}}$ \\
\hline C15 & $0.01 \pm 0.02^{\mathrm{a}}$ & $0.02 \pm 0.01^{b}$ & $0.80 \pm 0.15^{d}$ & $355 \pm 0.21^{a}$ & $820 \pm 2.45^{d}$ \\
\hline C30 & $0.02 \pm 0.01^{b}$ & $0.03 \pm 0.02^{c}$ & $0.93 \pm 0.1^{b}$ & $280 \pm 0.15^{b}$ & $410 \pm 1.34^{c}$ \\
\hline C45 & $0.05 \pm 0.01^{c}$ & $0.04 \pm 0.01^{d}$ & $1 \pm 0.05^{\mathrm{a}}$ & $165 \pm 0.1^{c}$ & $380 \pm 3.5^{b}$ \\
\hline C100 & $0.11 \pm 0.04^{d}$ & $0.05 \pm 0.011^{e}$ & $1.07 \pm 0.01^{c}$ & $95 \pm 0.24^{d}$ & $320 \pm 2.45^{a}$ \\
\hline \multicolumn{6}{|l|}{ Synthetic standards } \\
\hline $\mathrm{BHT}\left(\mathrm{IC}_{50}, \mathrm{mg} / \mathrm{mL}\right)$ & - & - & - & $46.6 \pm 0.08$ & - \\
\hline Ascorbic acid $\left(\mathrm{EC}_{50}, \mathrm{mg} / \mathrm{mL}\right)$ & - & - & - & - & $68 \pm 0.06$ \\
\hline
\end{tabular}

${ }^{a}\left(m g\right.$ GAE/g), ${ }^{b}(m g ~ Q E / g),{ }^{c}\left(C_{50}, \mu g / m L\right),{ }^{d}\left(E C_{50}, \mu g / m L\right)$.

BHT: Butylated hydroxytoluene; TPC: total polyphenols content ; TFC: total flavonoids content ; CTC: Condensed tannins content; CC: control cookies; C15, C30, C45, and C100: cookie samples containing the wheat flour:ZLP in the ratio of 85:15, 70:30, 55:45, 0:100, respectively.BHT: butylated hydroxytoluene. an values with different superscripts in the same column differ significantly (Duncan's LSD test, $p<0.05$ ). 
freeze-dried Japanese quince fruits (Antoniewska et al., 2019) and tomato powder in cookies (Bhat et al., 2020). Several authors also demonstrated that the DPPH radical scavenging activity and reducing power increased in cookies with baking temperature, which could be due to the formation of melanoidins produced in the Maillard reaction (Bhat et al., 2020). In addition, high concentration of bioactive compounds in ZLP lead to an increase in the antioxidant potential of formulated cookies. This could be of interest for human health and could provide an extended shelf life of cookies for food industry.

\section{FTIR analysis}

The FTIR spectra of cookie samples in the range of $400-4,000 \mathrm{~cm}^{-1}$ are revealed in Figure 3. Results revealed that cookie samples demonstrated common peaks with small variations in intensity. In all cookie samples, major peaks were observed at $3,500 \mathrm{~cm}^{-1}$ and $2,800 \mathrm{~cm}^{-1}$, which indicated the stretch vibrations of $\mathrm{O}-\mathrm{H}$ groups. In addition, the observed peak at $2,943 \mathrm{~cm}^{-1}$ resulted from the stretching vibration of $\mathrm{C}-\mathrm{H}$ bond. However, the peaks found between $1,645 \mathrm{~cm}^{-1}$ and $1,742 \mathrm{~cm}^{-1}$ were attributed to the $\mathrm{C}-\mathrm{O}$ stretch vibration of $\alpha, \beta$-unsaturated compound. Similar results were reported by Tyagi et al. (2020) on cookies enriched with Tinospora cordifolia stem powder. The observed peaks at $1,485.71 \mathrm{~cm}^{-1}$ were essentially assigned to water molecules absorbed in the amorphous region. The established peaks at a range of 1,142-1,000 $\mathrm{cm}^{-1}$ could be attributed to the $\mathrm{C}-\mathrm{O}$ bond and aliphatic $\mathrm{C}-\mathrm{N}$ stretching; these peaks were with higher intensities in cookie samples enriched with ZLP compared to $\mathrm{CC}$ sample. These peaks are related to the presence of phenolic compounds, $\beta$-glycoside and glucoside (Tyagi et al., 2020), which were essentially present in
ZLP. Besides, decrease in the intensity of peaks in cookie samples reflects their change in crystallinity.

\section{Thermogravimetric analysis}

In general, when materials are heated, they lose weight because of simple processes, such as drying, or because of chemical reactions that release gasses (Blanco Canalis et al., 2018). The observed weight loss, which was related to reduction of water by evaporation can provide valuable information about the volatile and heat labile compounds present in cookie samples and their thermal stability. The TGA and differential TGA (Dr-TGA) curves of cookie samples are revealed in Figure 4(a) and Figure 4(b). The TGA of all studied cookie samples demonstrated four typical stages of weight loss. Figure 4(b) indicates that no significant differences in shape and intensity were observed between C45 and C100 samples. Comparison between the cookies enriched with ZLP and control samples indicated that the maximum rate of weight loss was in C45 sample (92.69\%) followed by C100 (91.72\%). The first stage of weight loss ranged from $190^{\circ} \mathrm{C}$ to $211^{\circ} \mathrm{C}$, and was attributed to the loss of free and bound water with increasing temperature. It is suggested that inclusion of ZLP in cookies reduced the amount of water available for protein hydration, allowing faster water evaporation. In addition, the observed increase in weight loss suggested the formation of a weak gluten network in cookies dough. According to Blanco Canalis et al. (2018), water in cookies dough is shared between different components (such as starch, gluten and sucrose) responsible for trapping water until it is released because of heating. The second, third and fourth stages ranged from $229.54^{\circ} \mathrm{C}$ to $254.38^{\circ} \mathrm{C}, 311.85^{\circ} \mathrm{C}$ to $373.63^{\circ} \mathrm{C}$ and $426.29^{\circ} \mathrm{C}$ to $470.3^{\circ} \mathrm{C}$, respectively. The second stage represented

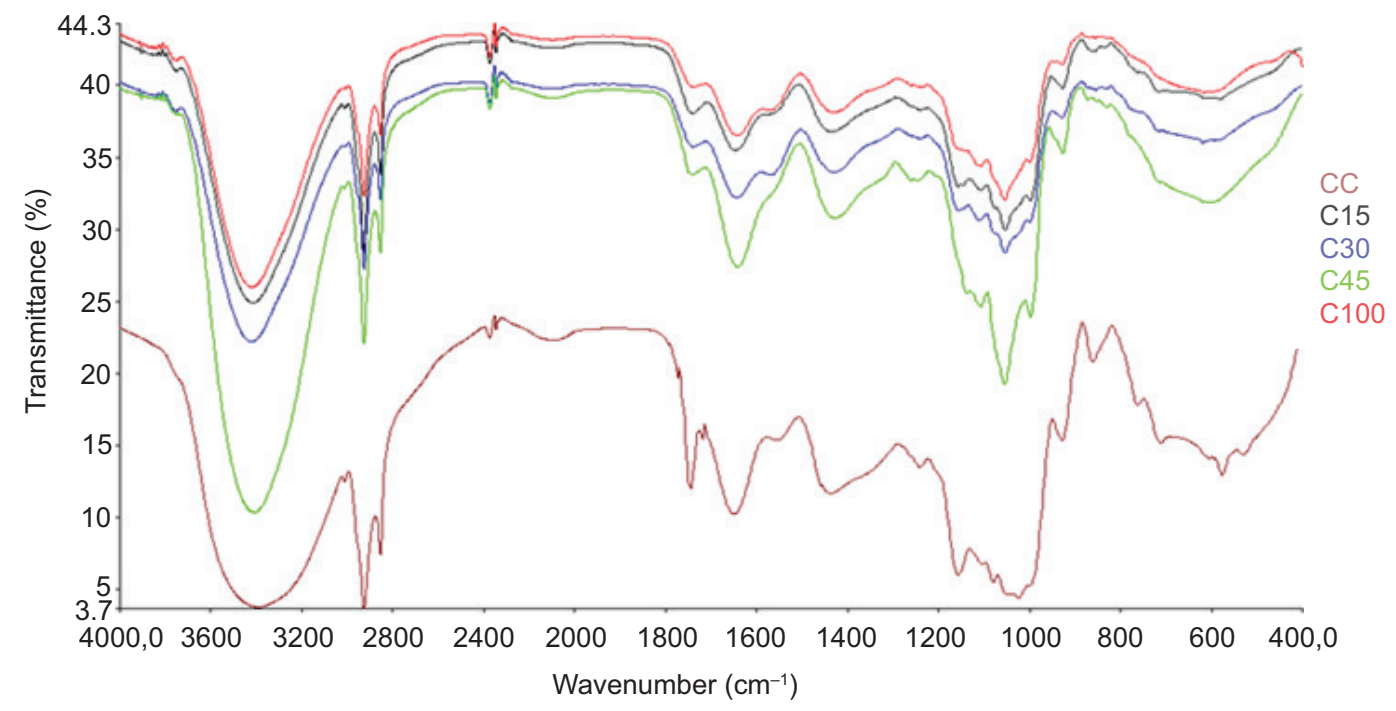

Figure 3. FTIR spectra of cookie samples; CC: control cookies; C15, C30, C45 and C100 are cookie samples containing wheat flour:ZLP in the ratio of $85: 15,70: 30,55: 45$ and $0: 100$, respectively. 

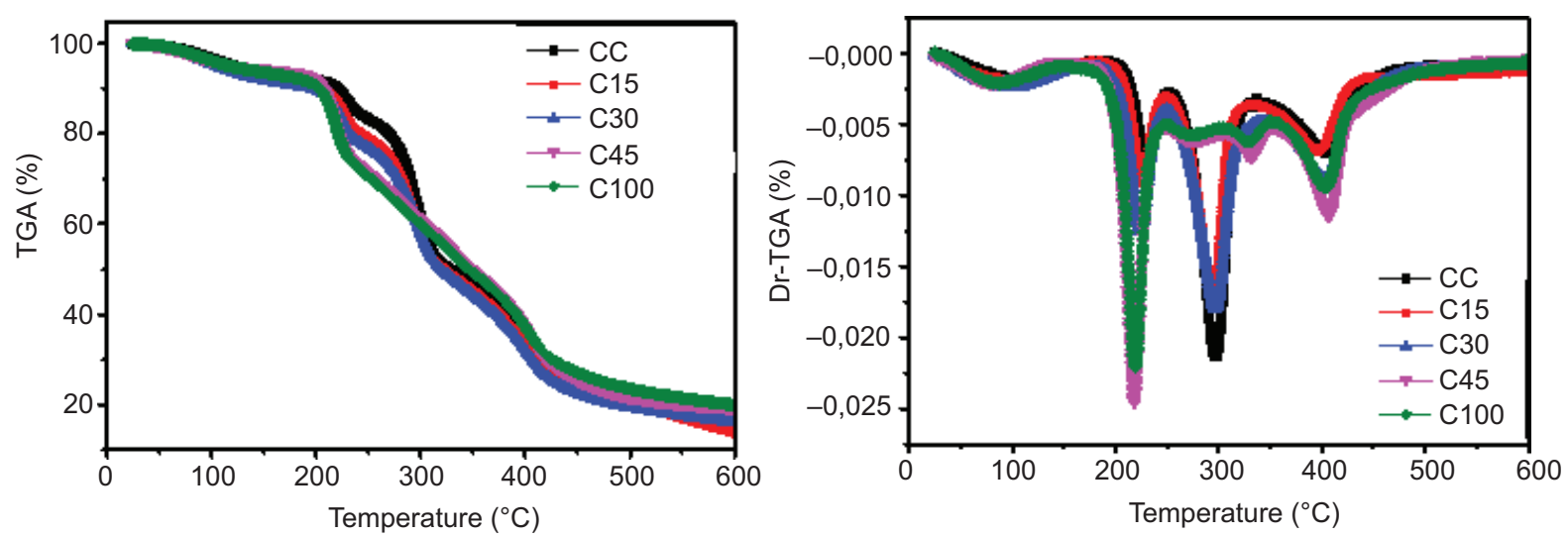

Figure 4. (A) Thermogravimetric, and (B) differential thermogravimetric curves of cookie samples; CC: control cookies; C15, C30, C45 and C100 are cookie samples containing wheat flour:ZLP in the ratio of 85:15, 70:30, 55:45, 0:100, respectively.

the depolymerization and degradation of organic matter (starch, gluten and polysaccharides). However, the third stage of weight loss represented the oxidation of organic matter that lead to the formation of ash residue. In the last range of temperature (close to $500^{\circ} \mathrm{C}$ ), the total weight loss measured for cookie samples was not noticeably different.

\section{Microstructure of cookie samples}

Scanning electron microscopy was used to study the microstructure of baked cookie samples. The microstructure observation indicated that the protein network matrix was well developed and the starch granules were more intact in the case of control cookies (Figure 5). However, a change in the structure of cookies was observed with increase in ZLP content. This change was strongly observed in the case of $\mathrm{C} 100$ sample. Alteration in the microstructure of cookies could be due to the richness of ZLP in polysaccharides, which have good water retention capacity; this could also be due to the gelatinization of starch and denaturation of protein matrix. These results are in agreement with those found by Adebiyi et al. (2016), who reported a similar microstructure of cookies enriched with millet flours.

\section{Sensory evaluation of cookies}

The flavor, color, texture, after-taste and overall acceptability scores recorded for the cookies enriched with ZL powder are depicted in Table 4. Results of sensory evaluation revealed that color, flavor and after-taste parameters increased with increase of ZLP in cookies, reaching the values of 7.87, 8.89 and 3.20 , respectively, noted essentially in C100 sample. The sensory evaluation of cookies' color surface paralleled the colorimetric measurement (Table 3), with ZLP-enriched cookies being darker than the control. In addition, increase in ZLP concentration demonstrated a decrease in texture parameter in comparison to control cookies; these results were in agreement with the instrumental data of hardness and fracturability
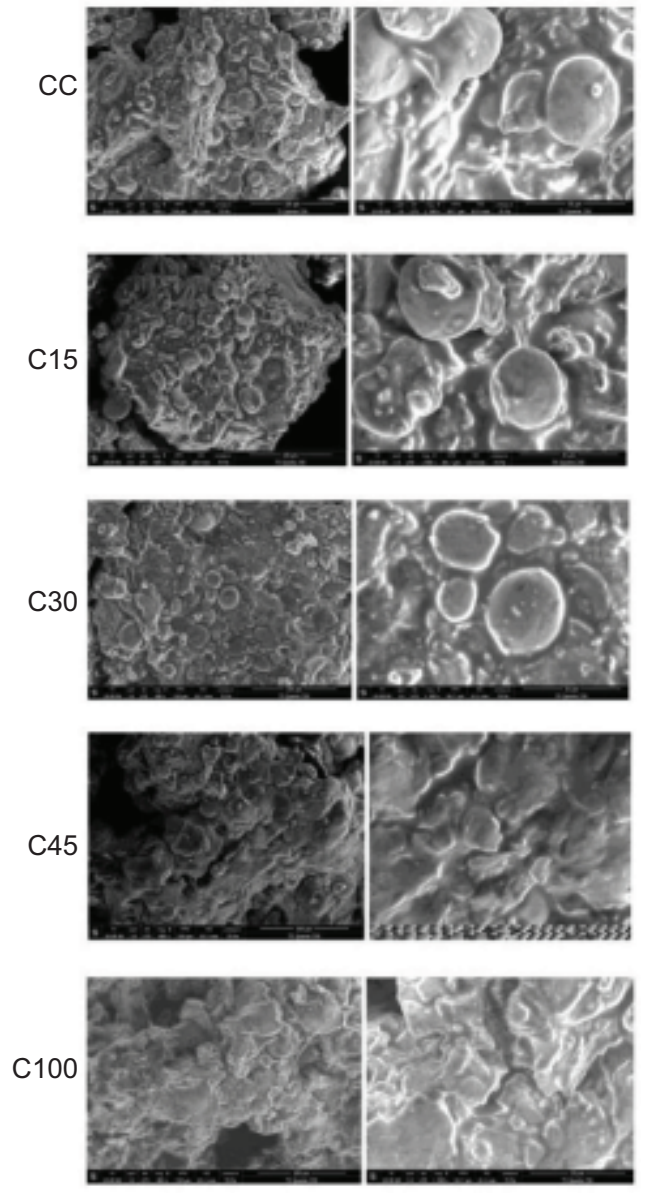

Figure 5. SEM of cookies samples. Magnification $\times 400$ and $\times 500$; CC: control cookies. C15, C30, C45, C100 are cookies samples containing wheat flour: ZLP $(85: 15,70: 30,44: 45$, $0: 100)$.

(Table 3). Similar effect was reported by Krystyjan et al. (2015), Saadoudi et al. (2017) and Šaponjac et al. (2016) with cookies enriched with bee pollen, jujube, and sour cherry pomace extract, respectively. In all enriched cookies, the C15 sample had a sensory score near to the CC 
Table 5. Sensory acceptability of both control and formulated cookies.

\begin{tabular}{lccccc} 
Cookies & Color & Flavor & After-taste & Texture & Overall acceptability \\
\hline CC & $4.27 \pm 1.12^{\mathrm{a}}$ & $6.54 \pm 0.71^{\mathrm{c}}$ & $8.47 \pm 1.30^{\mathrm{a}}$ & $6.60 \pm 1.60^{\mathrm{b}}$ & $7.20 \pm 2.04^{\mathrm{a}}$ \\
C15 & $5.20 \pm 1.00^{\mathrm{b}}$ & $7.33 \pm 0.63^{\mathrm{c}}$ & $7.93 \pm 0.96^{\mathrm{a}}$ & $5.66 \pm 1.13^{\mathrm{a}, \mathrm{b}}$ & $6.47 \pm 1.30^{\mathrm{b}}$ \\
C30 & $5.60 \pm 0.64^{\mathrm{b}}$ & $7.41 \pm 1.03^{\mathrm{c}}$ & $7.33 \pm 1.05^{\mathrm{a}}$ & $5.06 \pm 1.03^{\mathrm{c}}$ & $5.00 \pm 1.31^{\mathrm{a}, \mathrm{b}}$ \\
C45 & $6.67 \pm 0.63^{\mathrm{c}}$ & $8.27 \pm 0.52^{\mathrm{d}}$ & $5.36 \pm 1.39^{\mathrm{b}}$ & $4.87 \pm 1.44^{\mathrm{a}}$ & $4.68 \pm 1.25^{\mathrm{a}}$ \\
C100 & $7.87 \pm 0.63^{\mathrm{c}}$ & $8.89 \pm 0.41^{\mathrm{d}}$ & $3.20 \pm 2.01^{\mathrm{b}}$ & $4.07 \pm 1.74^{\mathrm{a}}$ & $4.20 \pm 2.61^{\mathrm{a}}$ \\
\hline
\end{tabular}

Values are expressed as mean \pm standard deviation of three determinations. Mean values with different superscripts in the same column differ significantly $(p<0.05)$. CC: control cookies; C15, C30, C45 and C100 are cookie samples containing wheat flour:ZLP in the ratio of 85:15, 70:30, $55: 45,0: 100$, respectively.

sample. For the overall acceptability of results, $\mathrm{CC}$ and C15 samples were most acceptable, while C100 sample was not preferred by panelists. Masmoudi et al. (2021) established that biscuits supplemented with jujube flour had as acceptable quality as the control for all its doses (5\%, $10 \%$ and $15 \%)$. Reduction in acceptability of cookies at higher level of substitution with ZLP was due to more plant undertones contributed by ZLP. Similar effect was reported for cookies supplemented with flaxseed flour (Kaur et al., 2017) and Japanese quince fruit (Antoniewska et al., 2019).

\section{Conclusion}

The results of the present study reveal that ZLP contains several bioactive components, fatty acids, phenolics and antioxidants that are beneficial for human health. Results demonstrate that this powder has a great nutritional potential to be used in food industry and to substitute the conventional wheat flour in the formulation of new functional cookies. Addition of ZLP improves the phytochemical composition and the antioxidant potential of formulated cookies as revealed by the increase in DPPH and reducing power values in cookies. The FTIR and TGA results revealed the presence of many bioactive compounds in ZLP and formulated cookies. Besides improving the nutritional value, addition of ZLP affects the appearance, physicochemical, textural and sensorial properties of formulated cookies. Based on the sensory analysis, it is concluded that the acceptability of formulated cookies is directly dependent on the amount of added ZLP, and cookies enriched with 15\% ZLP (C15) seems to have gathered the overall preference of panelists.

\section{Acknowledgments}

This work was supported by the Ministry of Higher Education and Scientific Research, Tunisia and the
Ministry of Agriculture, Water Resources and Maritime Fisheries, Tunisia. The authors wish to thank the technical staff, particularly Hanen Nasri and Nesrine Haj Yahya, for their valuable contribution in performing various analyses. We are also grateful to Tesnim Zarroug for her valuable efforts to check proofs of this paper.

\section{Declaration of Interest}

The authors declare that they have no known competing financial interests or personal relationships that could have influenced the research reported in this paper.

\section{References}

Abdeddaim M., Lombarkia O., Bacha A., Fahloul D., Abdeddaim D., Farhat R., Saadoudi M., Noui Y and Lekbir A. 2014. Biochemical characterization and nutritional properties of Zizyphus lotus $\mathrm{L}$. fruits in Aures region, northeastern of Algeria. Ann Food Sci Technol. 15(1):75-81.

Aboshora W., Yu J., Omar K.A., Li Y., Hassanin H.A.M., Navicha W.B. and Zhang L. 2019. Preparation of Doum fruit (Hyphaene thebaica) dietary fiber supplemented biscuits: influence on dough characteristics, biscuits quality, nutritional profile and antioxidant properties. J Food Sci Technol. 56:1328-1336. https://doi.org/10.1007/s13197-019-03605-Z

Adebiyi J.A., Obadina A.O., Mulaba-Bafubiandi A.F., Adebo O.A. and Kayitesi E. 2016. Effect of fermentation and malting on the microstructure and selected physicochemical properties of pearl millet (Pennisetum glaucum ) flour and biscuit. J Cereal Sci. 70:132-139. https://doi.org/10.1016/j.jcs.2016.05.026

Ajila C.M., Leelavathi K. and Prasada Rao U.J.S. 2008. Improvement of dietary fiber content and antioxidant properties in soft dough biscuits with the incorporation of mango peel powder. J Cereal Sci. 48:319-326. https://doi.org/10.1016/j.jcs.2007.10.001

Anderson R.A., Conway H.F. and Peplinski A.J. 1970. Gelatinization of corn grits by roll cooking, extrusion cooking and steaming. Starch-Starke. 22(4):2-7. https://doi.org/10.1002/star. 19700220408 
Antoniewska A., Rutkowska J. and Pineda M.M. 2019. Antioxidative, sensory and volatile profiles of cookies enriched with freeze-dried Japanese quince (Chaenomeles japonica) fruits. Food Chem. 286:376-387. https://doi.org/10.1016/j. foodchem.2019.02.029

Association of Official Analytical Chemists (AOAC). 2005. Official methods of analysis of AOAC international, 18th ed. Washington DC: AOAC.

Bakhtaoui F.Z., Lakmichi H., Megraud F., Chait A. and Gadhi C.E.A. 2014. Gastro-protective, anti-Helicobacter pylori and antioxidant properties of Moroccan Zizyphus lotus L. J Appl Pharm Sci. 4(10):81-87. https://doi.org/10.7324/JAPS.2014.401015

Bhat N.A., Wani I.A. and Hamdani A.M. 2020. Tomato powder and crude lycopene as a source of natural antioxidants in whole wheat flour cookies. Heliyon. 6(1):03042. https://doi. org/10.1016/j.heliyon.2019.e03042

Blanco Canalis M.S., Baroni M.V., León A.E. and Ribotta P.D. 2020. Effect of peach puree incorportion on cookie quality and on simulated digestion of polyphenols and antioxidant properties. Food Chem. 333:127464. https://doi.org/10.1016/j. foodchem.2020.1274.64

Blanco Canalis M.S., León A.E. and Ribotta P.D. 2018. Incorporation of dietary fiber on the cookie dough. Effects on thermal properties and water availability. Food Chem. 7:146. https://doi. org/10.1016/j.foodchem.2018.07.146

Chieh C. 2006. Water. In: Y.H. Hui (Ed.), Bakery Products Science and Technology (pp. 211-232). Blackwell Oxford, UK. https:// doi.org/10.1002/9780470277553.ch11

Choi S.Y., Yoon B.R. and Kim S.S. 2016. Characteristics and nutritional compositions of two jujube varieties cultivated in Korea. Korean J Food Preser. 23:127-130. https://doi.org/10.11002/ kjfp.2016.23.1.127

Chouaibi M., Mahfoudhi N., Rezig L., Donsì F., Ferrari G. and Hamdi S. 2011. Nutritional composition of Zizyphus lotus L. seeds. J Sci Food Agric. 92(6):1171-1177. https://doi.org/10.1002/jsfa.4659

Das Chagas E.G.L., Vanin F.M., dos Santos Garcia V.A., Yoshida C.M.P and de Carvalho R.A. 2020. Enrichment of antioxidants compounds in cookies produced with camu-camu (Myrciaria dubia) coproduct powders. LWT-Food Sci Technol. 137:110472. https://doi.org/10.1016/j.lwt.2020.110472

Da Silva F.L., Escribano-Bailón M.T., Alonso J.J.P., RivasGonzalo J.C. and Santos-Buelga C. 2007. Anthocyanin pigments in strawberry. LWT-Food Sci Technol. 40:374-382. https://doi. org/10.1016/j.lwt.2005.09.018

Dewanto V., Wu X., Adom K.K and Liu R.H. 2002. Thermal processing enhances the nutritional value of tomatoes by increasing total antioxidant activity. J Agric Food Chem. 50:3010-3014. https://doi.org/10.1021/jf0115589

Elfalleh W., Tlili N., Nasri N., Yahia Y., Hannachi H., Chaira N., Ying $\mathrm{M}$ and Ferchichi A. 2011. Antioxidant capacities of phenolic compounds and tocopherols from Tunisian pomegranate (Punica granatum) fruits. J Food Sci. 76:707-713. https://doi. org/10.1111/j.1750-3841.2011.02179.x

El Maaiden E., El Kharrassi Y., Lamaoui M., Allai L., Essamadi A.K., Nasser B., and Moustaid K. 2020. Variation in minerals, polyphenolics and antioxidant activity of pulp, seed and almond of different Zizyphus species grown in Morocco. Brazilian J Food Technol. 23:2019206. https://doi.org/10.1590/1981-6723. 20619

Ferreira I.C.F.R., Baptista P., Vilas-Boas M. and Barros L. 2007. Free-radical scavenging capacity and reducing power of wild edible mushrooms from northeast Portugal: individual cap and stipe activity. Food Chem. 100(4):1511-1516. https://doi. org/10.1016/j.foodchem.2005.11.043

Galla N.R., Pamidighantam P.R., Karakala B., Gurusiddaiah M.R and Akula S. 2017. Nutritional, textural and sensory quality of biscuits supplemented with spinach (Spinacia oleracea L.). Int J Gastron Food Sci. 7:20-26. https://doi.org/10.1016/j. ijgfs.2016.12.003

Ghalem M., Merghache S. and Belarbi M. 2014. Study on the antioxidant activities of root extracts of Zizyphus lotus from the western region of Algeria. Pharmacog J. 6:32-42. https://doi. org/10.5530/pj.2014.4.5

Ghazghazi H., Aouadhi C., Riahi L., Maaroufi A. and Hasnaoui B. 2014. Fatty acids composition of Tunisian Zizyphus lotus L.(Desf.) fruits and variation in biological activities between leaf and fruit extracts. Natural Prod Res. 28:1106-1110. https://doi. org/10.1080/14786419.2014.913244.

Ghedira K. 2013. Zizyphus lotus (L.) Desf.(Rhamnaceae): jujubier sauvage. Phytothérapie. 11(3):149-153. https://doi.org/10.1007/ s10298-013-0776-8

Hatano T., Kagawa H., Yasahara H.T. and Okuda T. 1988. The effect of extracts on DPPH radical was estimated according to the methanol. Food Chem. 78:347-354.

Hussai, S., Anjum F., Butt M., Khan M. and Asghar A. 2006. Physical and sensory attributes of flaxseed flour supplemented cookies. Turkish J Biol. 30:87-92.

Ismail T., Akhtar S., Riaz M. and Ismail A. 2014. Effect of pomegranate peel supplementation on nutritional, organoleptic and stability properties of cookies. Int J Food Sci Nutr. 65(6):661-666. https://doi.org/10.3109/09637486.2014.908170

Kaur P., Sharma P., Kumar V., Panghal A., Kaur J. and Gat Y. 2017. Effect of addition of flaxseed flour on phytochemical, physicochemical, nutritional, and textural properties of cookies. J Saudi Soc Agric Sci. 12:004.

Kaur M. and Singh N. 2005. Studies on functional, thermal and pasting properties of flours from different chickpea (Cicer arietinum L.) cultivars. Food Chem. 91:403-411. https://doi.org/10.1016/j. foodchem.2004.06.015

Koley T.K., Kaur C., Nagal S., Walia S., Jaggi S. and Sarika. 2016. Antioxidant activity and phenolic content in genotypes of Indian jujube (Zizyphus mauritiana Lamk.). Arab J Chem. 9:10441052. https://doi.org/10.1016/j.arabjc.2011.11.005

Krystyjan M., Gumul D., Ziobro R. and Korus A. 2015. The fortification of biscuits with bee pollen and its effect on physicochemical and antioxidant properties in biscuits. LWT-Food Sci Technol. 63(1):640-646. https://doi.org/10.1016/j.lwt.2015.03.075

Ksouri R., Megdiche W., Falleh H., Trabelsi N., Boulaaba M., Smaoui A. and Abdelly C. 2008. Influence of biological, environmental and technical factors on phenolic content and antioxidant activities of Tunisian halophytes. Comptes Rendus Biologies. 331:865-873. https://doi.org/10.1016/j.crvi.2008.07.024 
Le-Floc'h E. 1983. Contribution à une étude ethnobotanique de la flore de la Tunisie: programme flore et végétation Tunisienne (pp. 150-151). Publications Scientifiques Tunisiennes, Tunis.

Li J.W., Fan L.P., Ding S.D. and Ding X.L. 2007. Nutritional composition of five cultivars of Chinese jujube. Food Chem. 103:454460. https://doi.org/10.1016/j.foodchem.2006.08.016

Ludwig D.S., Hu F.B., Tappy L. and Brand-Miller J. 2018. Dietary carbohydrates: role of quality and quantity in chronic disease. BMJ (Sci Polit Nutr). 361:K2340. https://doi.org/10.1136/bmj. k2340

Marmouzi I., Kharbach M., El Jemli M., Bouyahya A., Cherrah Y., Bouklouze A. and Faouzi M.E.A. 2019. Antidiabetic, dermatoprotective, antioxidant and chemical functionalities in Zizyphus lotus leaves and fruits. Indust Crops Prod. 132:134-139. https:// doi.org/10.1016/j.indcrop.2019.02.007

Martínez R., Torres P., Meneses M.A., Figueroa J.G., PérezÁlvarez J.A. and Viuda-Martos M. 2012. Chemical, technological and in vitro antioxidant properties of mango, guava, pineapple and passion fruit dietary fibre concentrate. Food Chem. 135(3): 1520-1526. https://doi.org/10.1016/j.foodchem.2012.05.057

Masmoudi M., Yaich H., Borchani M., Mbarki R. and Attia H. 2021. Chemical, physical and sensory characteristics of biscuits enriched with jujube (Zizyphus lotus L.) flour and fiber concentrate. J Food Sci Technol. 58(4):1411-1419. https://doi. org/10.1007/s13197-020-04652-7

Mau J.L., Chao G.R and Wu K.T. 2001. Antioxidant properties of methanolic extracts from several ear mushrooms. J Food Agric Food Chem. 49:5461-5467. https://doi.org/10.1021/jf010637h

Milićević N., Sakač M., Hadnađev M., Škrobot D., Šarić B., Hadnađev T.D., Jovanov P. and Pezo L. 2020. Physico-chemical properties of low-fat cookies containing wheat and oat bran gels as fat replacers. J Cereal Sci. 95:103056. https://doi. org/10.1016/j.jcs.2020.103056

Mkadmini H.K., Jdey A., Abdelly C., Majdoub H. and Ksouri R. 2015. Optimization of ultrasound-assisted extraction of antioxidant compounds from Tunisian Zizyphus lotus fruits using response surface methodology. Food Chem. 184:80-89. https:// doi.org/10.1016/j.foodchem.2015.03.047

Molnar D., Brnčić S.R., Vujić L., Gyimes E. and Krisch J. 2015. Characterization of biscuits enriched with black currant and jostaberry powder. Croatian J Food Technol Biotechnol Nutr.10(1-2):31-36.

Naknaen P., Itthisoponkul T., Sondee A. and Angsombat N. 2016. Utilization of watermelon rind waste as a potential source of dietary fiber to improve health promoting properties and reduce glycemic index for cookie making. Food Sci Biotechnol. 25(2):415-424. https://doi.org/10.1007/s10068-016-0057-z

Okala A., Ladan M.J., Wasagu R.S.U and Shehu K. 2014. Phytochemical studies and in vitro antioxidant properties of Zizyphus mauritiana fruit extract. Int J Pharmacog Phytochem Res. 6(4):885-888.

Pareyt B. and Delcour J.A. 2008. The role of wheat flour constituents, sugar and fat in low moisture cereal based products: a review on sugar-snap cookies. Crit. Rev. Food Sci Nutr. 48:82439. https://doi.org/10.1080/10408390701719223
Pasqualone A., Bianco A.M., Paradiso V.M., Summo C., Gambacorta G. and Caponio F. 2014. Physico-chemical, sensory and volatile profiles of biscuits enriched with grape marc extract. Food Res Int. 65:385-393. https://doi.org/10.1016/j.foodres.2014.07.014

Patro B.S., Bauri A.K., Mishra S and Chattopadhyay S. 2005. Antioxidant activity of Myristica malabarica extracts and their constituents. J Agric Food Chem. 53:6912-6918. https://doi. $\operatorname{org} / 10.1021 /$ jf050861x

Richardson J.E., Chatrou L.W., Mols J.B., Erkens R.H.J. and Pirie M.D. 2004. Historical biogeography of two cosmopolitan families of flowering plants: Annonaceae and Rhamnaceae. Philos Trans Royal Soc B. 359:1495-1508. https://doi. org/10.1098/rstb.2004.1537

Rosell C.M., Cortez G. and Repo-Carrasco R. 2009. Breadmaking use of andean crops quinoa, kañiwa, kiwicha, and tarwi. Cereal Chem. 84(4):386-392. https://doi.org/10.1094/ CCHEM-86-4-0386

Ryan E., Galvin K., O'Connor T.P., Maguire A.R. and O'Brien N.M. 2007. Phytosterol, squalene, tocopherol content and fatty acid profile of selected seeds, grains, and legumes. Plant Foods Hum Nutr. 62(3):85-91. https://doi.org/10.1007/s11130-007-0046-8

Saadoudi M., Hambaba L., Abdeddaim M., Lekbir A., Bacha A., Boudraa S. and Zidani S. 2017. Nuritional composition, physical properties and sensory evaluation of biscuit produced from jujubes (fruits of zizyphus lotus L.). Ann Food Sci Technol. 18(3):395-401.

Sangnark A. and Noomhorm A. 2004. Chemical, physical and baking properties of dietary fiber prepared from rice straw. Food Res Int. 37:66-74. https://doi.org/10.1016/j.foodres.2003.09.007

Šaponjac V.T., Cetkovic G., Canadanovic-Brunet J., Pajin B., Djilas S., Petrovic J., Loncarevic I., Stajcic S. and Vulic J. 2016. Sour cherry pomace extract encapsulated in whey and soy proteins: incorporation in cookies. Food Chem. 207:27-33. https:// doi.org/10.1016/j.foodchem.2016.03.082

Sun B., Ricardo-da-Silva J.M. and Spranger I. 1998. Critical factors of vanillin assay for catechins and proanthocyanidins. J Agric Food Chem. 46:4267-4274. https://doi.org/10.1021/jf980366j

Takeungwongtrakul S. and Benjakul S. 2017. Biscuits fortified with micro-encapsulated shrimp oil: characteristics and storage stability. J Food Sci Technol. 54(5):1126-1136. https://doi. org/10.1007/s13197-017-2545-4

Toledo N.M.V. de, Nunes L.P., Silva P.P.M. Da Spoto M.H.F. and Canniatti-Brazaca S.G. 2017. Influence of pineapple, apple and melon by-products on cookies: physicochemical and sensory aspects. Int J Food Sci Technol. 52(5):1185-1192. https://doi. org/10.1111/ijfs.13383

Tyagi P., Chauhan A.K and Aparna. 2020. Optimization and characterization of functional cookies with addition of Tinospora cordifolia as a source of bioactive phenolic antioxidants. LWT-Food Sci Technol. 130:109639. https://doi.org/10.1016/j. lwt.2020.109639

Varastegani B., Zzaman W. and Yang T.A. 2015. Investigation on physicochemical and sensory evaluation of cookies substituted with papaya pulp flour. J Food Quality. 38(3):175-183. https:// doi.org/10.1111/jfq.12129 
Wojdyło A., Carbonell-Barrachina Á.A., Legua P. and Hernández F. 2016. Phenolic composition, ascorbic acid content, and antioxidant capacity of Spanish jujube (Zizyphus jujube Mill.) fruits. Food Chem. 201:307-314. https://doi.org/10.1016/j. foodchem.2016.01.090

Yamada H., Nagai T., Cyong J.C., Otsuka Y., Tomoda M. and Shimizu N. 1985. Relationship between chemical structure and anti-complementary activity of plant polysaccharides. Carbohydr Res. 144:101-111. https://doi.org/10.1016/00086215(85)85011-4

Zarroug Y., Mejri J., Dhawefi N., Ben. Sik. Ali S., EL Felah M. and Hassouna M. 2015. Comparison of chemical composition of two durum wheat (Triticum durum L.) and bread wheat (Triticum aestivum L.) germ oils. Ekin J Crop Breed Genet. 1(1):69-73. 